(2) Open Access Full Text Article

ORIGINAL RESEARCH

\title{
Immunostimulatory effects of the standardized extract of Tinospora crispa on innate immune responses in Wistar Kyoto rats
}

This article was published in the following Dove Press journal:

Drug Design, Development and Therapy

10 June 2015

Number of times this article has been viewed

\author{
Waqas Ahmad \\ Ibrahim Jantan \\ Endang Kumolosasi \\ Syed Nasir Abbas Bukhari \\ Drug and Herbal Research Centre, \\ Faculty of Pharmacy, Universiti \\ Kebangsaan Malaysia, Jalan Raja Muda \\ Abdul Aziz, Kuala Lumpur, Malaysia
}

Correspondence: Ibrahim Jantan Drug and Herbal Research Centre, Faculty of Pharmacy, Universiti Kebangsaan Malaysia, Jalan Raja Muda Abdul Aziz, 50300 Kuala Lumpur, Malaysia

Tel +60 I 62886445

Fax +60 32698327

Email profibj@gmail.com
Abstract: Tinospora crispa (TC) has been used in folkloric medicine for the treatment of various diseases and has been reported for several pharmacological activities. However, the effects of TC extract on the immune system are largely unknown. Therefore, the present study was aimed to investigate the immunomodulatory effects of a standardized $80 \%$ ethanol extract of the stem of TC on innate immune responses. Male Wistar Kyoto rats were treated daily at $100 \mathrm{mg} / \mathrm{kg}, 200 \mathrm{mg} / \mathrm{kg}$, and $400 \mathrm{mg} / \mathrm{kg}$ doses of the extract for 21 days by oral gavage. The immunomodulatory potential of TC was evaluated by determining its effect on chemotaxis and phagocytic activity of neutrophils isolated from the blood of rats. To further elucidate the mechanism of action, its effects on the proliferation of T- and B-lymphocytes and T-lymphocytes subsets (CD4+ and CD8+) and on the secretion of Th1 and Th2 cytokines were also monitored. The main components of the extracts, syringin and magnoflorine, were identified and quantitatively analyzed in the extracts by using a validated reversed-phase high-performance liquid chromatography method. It was observed that the chemotactic activity of neutrophils obtained from extract-treated rats increased as compared to controls. A dose-dependent increase in the number of migrated cells and phagocytosis activity of neutrophils was observed. Dose-dependent increase was also observed in the T- and B-lymphocytes proliferation stimulated with concanavalin A $(5 \mu \mathrm{g} / \mathrm{mL})$ and lipopolysaccharide $(10 \mu \mathrm{g} / \mathrm{mL})$, and was statistically significant at $400 \mathrm{mg} / \mathrm{kg}(P>0.01)$. Apart from cell-mediated immune response, the concentrations of Th1 (TNF- $\alpha$, IL-2, and IFN- $\gamma$ ) and Th2 (IL-4) cytokines were significantly increased in sera of rats treated with different doses as compared with the control group. From these findings, it can be concluded that TC possesses immunostimulatory activity and has therapeutic potential for the prevention of immune diseases.

Keywords: Tinospora crispa standardized extract, immunostimulation, neutrophil migration, phagocytosis, lymphocyte proliferation, T-lymphocyte phenotyping, Th1/Th2 cytokines

\section{Introduction}

The immune system is a sophisticated and intricate network comprising organs, tissues, special cells, and proteins that function collectively to protect the body against foreign invasions such as toxins, parasites, and germs. The main immune factors of antigen-specific immune responses include T-lymphocytes (such as cytotoxic T-cells, T-suppressor cells, and T-helper [Th] cells) and their cytokines. ${ }^{1}$ The state of good health is maintained by the regulation of several cellular and humoral factors functioning in the immunoregulatory mechanism. The immune system is involved in the pathophysiology and etiology of several diseases. The dysfunction of immune system causes a number of diseases such as cancer, infectious diseases, parasitic diseases, allergy, asthma, ulcerative colitis, and arthritis. ${ }^{2}$ The adjustment of immune responses 
to alleviate such diseases has been of interest for several years. An immunomodulator affects the immune system by inducing either immunosuppression or immunostimulation. The immunostimulation by natural substances is believed to be a promising way to prevent and cure diseases. ${ }^{3}$

Conventional medicines play a key role in suppressing and strengthening the host immune response. Herbal drugs possess immunomodulatory characteristics and normally act by suppressing or stimulating both specific and nonspecific immunities. ${ }^{4}$ A number of plants used in conventional medicines have been found to possess immunomodulating activities such as Barleria prionitis, ${ }^{5}$ Tinospora cordifolia, ${ }^{6}$ Withania somnifera, ${ }^{7}$ Chenopodium ambrosioides,${ }^{8}$ Actaea racemosa,${ }^{9}$ Asparagus racemosus, ${ }^{10}$ Cyrtomium macrophyllum, ${ }^{11}$ Phyllanthus amarus, Phyllanthus urinaria, ${ }^{12}$ and Uncaria perrottetii. ${ }^{13}$ Centella asiatica ${ }^{14}$ and Mangifera indica have been shown to change the immune function and possess a range of immunomodulatory effects. Recently, complementary and alternative medicines have gained attention in the treatment of several immune disorders. Increasingly among these are the plant-based extracts. The assessment of the immunomodulatory activity of plant extracts is an expanding area of research. Furthermore, medicinal plants used for immunomodulation can provide potential alternatives to conventional chemotherapies for a variety of diseases, especially when the host defense mechanism has to be activated under the conditions of impaired immune response.

Tinospora crispa (Wild) Hook $\mathrm{f}$ and Thomson (TC) is a tree that belongs to the family Menispermaceae. This species is widely used in Indonesia, Malaysia, and Thailand as a bitter tonic for the treatment of intermittent fever, urinary disorders, rheumatism, and jaundice. ${ }^{15}$ It has also been used in Chinese traditional medicine for the treatment of tropical ulcer-related disorders, scabies, fracture, fever, septicemia, and contusion. ${ }^{16} \mathrm{~A}$ decoction of the whole plant has been used for anti-diabetes and postpartum remedy in Malay traditional medicine. TC has been found to possess antiparasitic, antiatherosclerosis, antihyperglycemic, antioxidant, antibacterial, antiproliferative, cardiovascular, and immunomodulatory activities. ${ }^{17-20}$

In spite of all these prospects, no significant data are available in the literature regarding the immunomodulatory activity of TC. Thus, the present study was aimed to investigate the immunomodulatory effects of TC using an in vivo animal model. The immunomodulatory effects of a standardized $80 \%$ ethanol extract of the stem of TC on innate immune response were assessed via a number of immune response assays.

\section{Materials and methods Chemicals and reagents}

Lipopolysaccharide (LPS), concanavalin A (Con A), fluorescein isothiocyanate (FITC)-labeled opsonized Escherichia coli, luminol (3-aminophthalhydrazide), phosphate-buffered saline (PBS) tablet, Hank's balanced salts solution (HBSS), ficoll, RPMI-1640 medium, fetal bovine serum (FBS), trypan blue reagent, and phorbol 12-myristate 13-acetate were purchased from Sigma-Aldrich Co. (St Louis, MO, USA). Lymphoprep $^{\mathrm{TM}}$ was obtained from Axis-Shield PoC AS (Oslo, Norway). Fetal calf serum was obtained from PAA Laboratories (Dartmouth, Massachusetts, USA), and BD Pharm Lyse ${ }^{\mathrm{TM}}$ lysing solution, FITC-conjugated anti-mouse $\mathrm{CD} 3, \mathrm{CD} 8$, phycoerythrin (PE)-conjugated CD4, APC-conjugated CD11b, FITC-conjugated CD18, and immunoglobulin G-FITC were obtained from Becton Dickinson (Franklin Lakes, NJ, USA). CytoSelect ${ }^{\circledR} 24$-well cell migration assay kits were purchased from Cell Biolabs, Inc. (San Diego, CA, USA). Levamisole was obtained from Cayman Chemical (Ann Arbor, MI, USA). Chemiluminescence measurements were carried out on a Luminoskan ${ }^{\mathrm{TM}}$ Ascent luminometer (Thermo Fisher Scientific). Fluorescence reading was performed using Varioskan ${ }^{\mathrm{TM}}$ flash multimode reader (Thermo Fisher Scientific). Enzyme-linked immunosorbent assay was performed using ProcartaPlex rat immunoassay kit (eBioscience, San Diego, CA, USA) and measured using Luminex instrument (Luminex 100, Mapix instrument). Phagotest kit was obtained from Glycotope Technology, Heidelberg, Germany. The flow cytometer BD FACSCanto II equipped with $488 \mathrm{~nm}$ argon-ion laser was used. $\mathrm{A} \mathrm{CO}_{2}$ incubator (Shel Lab, USA) and light microscope were also used in the bioassays. Highperformance liquid chromatography (HPLC) (Waters 2998) (Leitz Wetzlar, Wetzlar, Germany) was used for qualitative and quantitative analyses of the extract. Standard compounds, syringin (99.0\% purity) and magnoflorine ( $99.0 \%$ purity), were purchased from ChromaDex (Irvine, CA, USA). Methanol, acetonitrile, and trifluoroacetic acid of HPLC grade were purchased from Thermo Fisher Scientific. ${ }^{3} \mathrm{H}$-thymidine and scintillation cocktail (Ultima Gold MV) were purchased from PerkinElmer Inc. (Waltham, MA, USA). Radioactivity was measured using a Tri-Carb 3110 TR PerkinElmer Liquid Scintillation Counter (PerkinElmer Inc.).

\section{Plant collection}

The whole plants of TC were collected from Marang, Kuala Terengganu, Malaysia. The specimens were sent for authentication and identification. The specimens were identified by Dr Abdul Latif Mohamad of Faculty of Science and 
Technology, Universiti Kebangsaan Malaysia (UKM), and the voucher specimen (No UKMB 40178) was deposited at the Herbarium of UKM, Bangi, Malaysia.

\section{Preparation of plant extracts}

The stems of TC were grounded and extracted with $80 \%$ $\mathrm{EtOH}(3 \times 3 \mathrm{~L})$ at room temperature for 72 hours and then filtered through Whatman No 1 filter paper (Whatman plc, Maidstone, UK). The filtrate was collected, and excess solvent was evaporated under reduced pressure using a rotary evaporator at a temperature between $55^{\circ} \mathrm{C}$ and $60^{\circ} \mathrm{C}$. The extract was resuspended in $10 \%$ Tween 20 solution before being orally administered to rats.

\section{Standardization of the TC extract}

HPLC was performed on a Waters (USA) instrument equipped with a 2998 Photodiode Array Detector. The extract was analyzed on an RP, Xbridge ${ }^{\circledR} \mathrm{C} 18$ column $(5 \mu \mathrm{m}$, $250 \mathrm{~mm} \times 4.6 \mathrm{~mm}$ id; Waters, Ireland). The mobile phase consisted of acetonitrile and water $+0.02 \%$ of trifluoroacetic acid. The analysis was carried out using an isocratic elution at 10:90 acetonitrile-water for 10 minutes, followed by gradient changing to $25: 75$ over a period of 25 minutes. The flow rate was $1.2 \mathrm{~mL} / \mathrm{min}$; the UV traces were measured at $254 \mathrm{~nm}$, and the UV spectra (DAD) were recorded between $210 \mathrm{~nm}$ and $380 \mathrm{~nm}$. The TC extract (TCE) was standardized on basis of standard compounds, syringin and magnoflorine. In all, $100 \mathrm{mg}$ of TCE was dissolved in $1 \mathrm{~mL}$ of methanol and filtered through $0.45 \mu \mathrm{m}$ Millipore filter before injection into the HPLC system. The validation of HPLC for the standardization of extract was carried out by determination of linearity, precision, limit of quantification (LOQ), and limit of detection (LOD). The presence of standard compounds' syringin and magnoflorine in TCE, identified by comparison of their retention times and UV spectra with those of standards, respectively, run individually.

\section{Animals and experimental design}

All procedures in animal studies were carried out under a protocol approved by the UKM Animal Ethical Committee. Male Wistar Kyoto rats of inbred strains (6-8 weeks old) were obtained from Universiti Sains Malaysia. Animals were quarantined for at least 1 week before the start of study. Three rats were housed per cage in plastic shoe box cages. Animal rooms were maintained at $18^{\circ} \mathrm{C}-26^{\circ} \mathrm{C}$ with a relative humidity of $40 \%-70 \%$ and a 12 -hour light/dark cycle. The animals were kept on standard pellet diet, and ad libitum tap water access was provided. After being adapted to the environment for 1 week, the rats were randomly divided into six groups. Each experimental group consisted of six animals (Figure 1).

All animals were administered a daily oral dose of $1 \mathrm{~mL} / 100 \mathrm{~g}(\mathrm{v} / \mathrm{w})$ body weight. The animals were treated orally

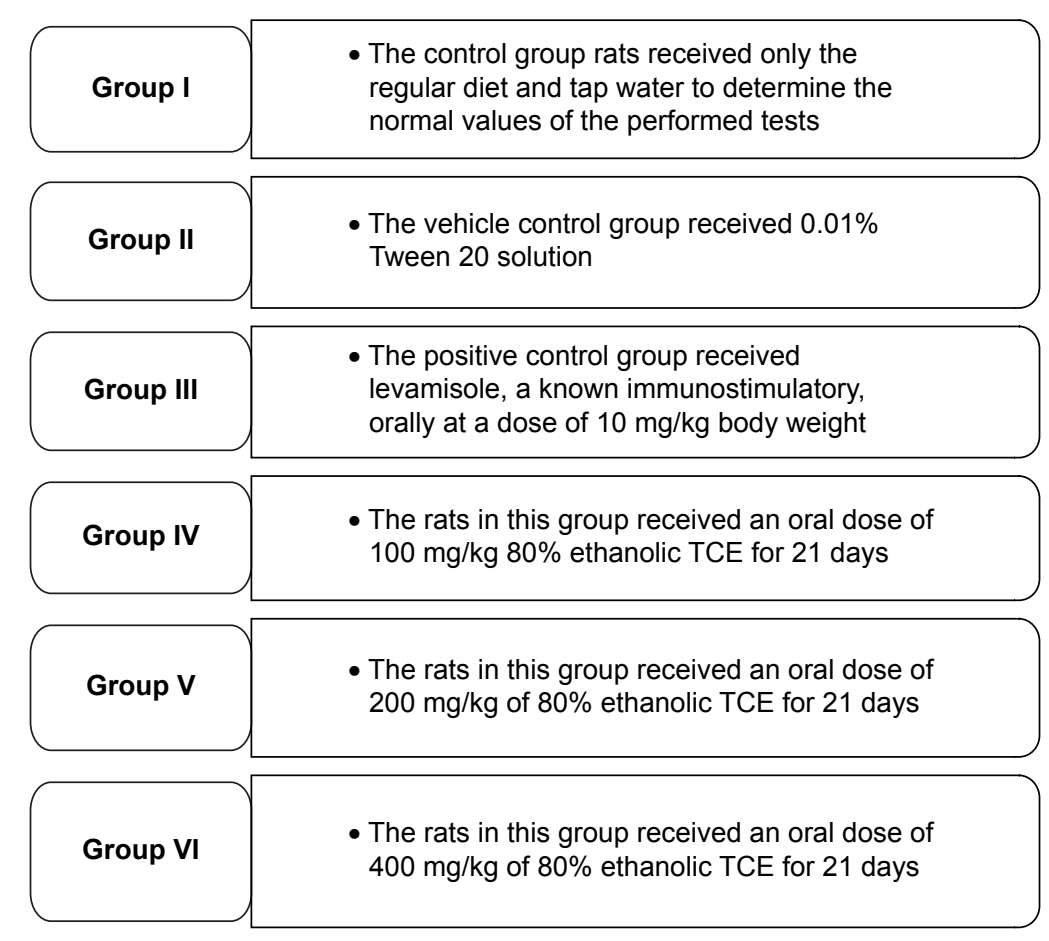

Figure I Randomly divided six groups of Wistar Kyoto rats. Abbreviation: TCE, Tinospora crispa extract. 
with the vehicle or extract for 14 days prior to immunization. The animals were immunized at $5.0 \times 10^{8}$ sheep red blood cells (SRBCs) per milliliter intraperitoneally on day 15. The body weights were monitored regularly, and dosing volumes were adjusted accordingly. At the end of the study, the rats were anesthetized with ether, and $5 \mathrm{~mL}$ blood was collected from their retro-orbital plexus. The rats were then euthanized by cervical dislocation, and the organs were collected.

\section{Isolation of neutrophil from rat whole blood}

The neutrophils were isolated from the whole blood of treated rats, which was drawn before immunization. It was carried out using modified Histopaque gradient technique. ${ }^{21}$ Briefly, $5 \mathrm{~mL}$ of Lymphoprep ${ }^{\circledR}$ was placed into a $10 \mathrm{~mL}$ falcon tube and an equal volume of rat whole blood was carefully layered on gradient without any break to the gradient. The falcon tube containing two-step gradients of Lymphoprep ${ }^{\circledR}$ and blood was centrifuged at $400 \times g$ for 45 minutes. Two distinct phases of plasma and Lymphoprep ${ }^{\circledR}$ gradient were found, while the mononuclear cells were retained at the sample/medium interface. The erythrocytes and neutrophils with high density sedimented through the Lymphoprep ${ }^{\circledR}$. The erythrocytes were then lysed by using Pharm Lyse ${ }^{\mathrm{TM}}$ lysing solution. At the end of incubation, the falcon tube was centrifuged at $200 \times \mathrm{g}$ for 5 minutes. The supernatant was aspirated carefully without disturbing the pellet and resuspended in PBS buffer. The viability of cells was checked with trypan blue exclusion method.

\section{Neutrophil migration assay}

The effect on the migration of neutrophils was quantitatively assessed using CytoSelect 24-Well Cell Migration Assay kits (Cell Biolabs, Inc.). The cell suspension containing $1.5 \times 10^{6}$ cells in $300 \mu \mathrm{L}$ serum-free media was added to the upper chamber (polycarbonate membranes insert with $3 \mu \mathrm{m}$ pore size filters) in a 24-well tissue culture plate. Subsequently, $500 \mu \mathrm{L}$ RPMI medium containing 10\% FBS was added to the lower chambers of the 24 -well plate as a chemoattractant. The cell suspension was left inside each insert to migrate for 2.5 hours at $37^{\circ} \mathrm{C}$ and $10 \% \mathrm{CO}_{2}$. The insert was then transferred to a new well containing cell detachment solution and incubated at $37^{\circ} \mathrm{C}$ and $10 \% \mathrm{CO}_{2}$ for 30 minutes to dislodge cells. Lysis buffer/CyQuant GR dye solution was added to stain the dislodged cells. ${ }^{22}$ The number of cells migrating to lower chambers was determined by fluorescence as per manufacturer's instructions on a Varioskan ${ }^{\mathrm{TM}}$ flash multimode reader (Thermo Fisher Scientific).

\section{Determination of Mac-I expression}

The CD11b/CD18 integrin expression assay was performed by flow cytometry (FACS). The aliquots $(100 \mu \mathrm{L})$ of neutrophils isolated from rat whole blood were stimulated with $N$-formyl-methionyl-leucyl-phenylalanine (fMLP) $(1 \mu \mathrm{M})$ for 90 minutes at $37^{\circ} \mathrm{C}$ in a $\mathrm{CO}_{2}$ incubator. The reaction was stopped by transferring all the tubes simultaneously into ice bath. Afterward, $10 \mu \mathrm{L}$ of CD11b-PE, CD18-FITC, or immunoglobulin G-FITC (negative control) was added into the mixture. All the tubes were incubated on ice for 60 minutes. The FACS lysing solution was added into each tube and incubated in the dark for 20 minutes to lyse red blood cells (RBCs). The tubes were centrifuged at $250 \times g$ for 5 minutes at $4{ }^{\circ} \mathrm{C}$, the supernatant was removed from the tubes, and the cells were washed with PBS. Subsequently, $0.5 \mathrm{~mL}$ of PBS was added into each tube and the expression of adhesion molecules was determined by FACS. The specific mean fluorescence intensity for cells stained by each antibody is reported as percentage of CD1 1b/CD18 expression. For each sample, 10,000 cells were analyzed.

\section{Determination of phagocytosis}

The neutrophils were isolated from the whole blood collected from treated rats via the retro-orbital method. The effect on the phagocytic activity of the neutrophils was determined by a commercially available kit. The assay was performed according to the manufacturer's protocol. Briefly, $100 \mu \mathrm{L}$ suspension of neutrophil was incubated with $20 \mu \mathrm{L}$ FITC-labeled $E$. coli in a shaking water bath at $37^{\circ} \mathrm{C}$ for 10 minutes. At the end of incubation, phagocytosis was quenched by the addition of icecold quenching solution to the mixture. After the final wash, cells were resuspended in DNA staining solution to exclude the aggregation artifacts of bacteria or cells, and analysis was done by FACS. The phagocytic potential was evaluated in leukocytes. Live populations were gated by the software program in the scatter diagram (forward-scattered light versus side-scattered light). The phagocytic activity was determined as the percentage of phagocytizing neutrophils and monocytes.

\section{Preparation of splenocytes}

The spleen from TCE-treated and -untreated animals (which were intraperitoneally immunized with $5.0 \times 10^{8} \mathrm{SRBC} / \mathrm{mL}$ 2 weeks after treatment) was aseptically removed. The animals were sacrificed by cervical dislocation. The abdominal cavity was incised to remove the spleen. The tissue was placed into a sterile dish containing HBSS. The spleen was minced using a pair of scissors and passed through a fine nylon cell strainer with pore size of $70 \mu \mathrm{m}$ obtained from 
Becton Dickinson. The excised spleen was pressed through the strainer using plunger at the end of a syringe. The cells were washed through the strainer with excess HBSS. The cell suspension was then centrifuged at 1,600 rpm for 5 minutes. The supernatant was aspirated, and the pellet was resuspended in $2 \mathrm{~mL}$ prewarmed (at $37^{\circ} \mathrm{C}$ ) $\mathrm{BD}$ Pharm Lyse ${ }^{\mathrm{TM}}$ lysing solution to lyse the RBCs. ${ }^{23}$ The cells were lysed at room temperature for 3 minutes at $37^{\circ} \mathrm{C}$. The cells were then centrifuged at 1,600 rpm for 5 minutes. The pelleted cells were washed three times with PBS after centrifugation. The supernatant was discarded, and the pelleted cells were resuspended in RPMI-1640 (Sigma-Aldrich Co.) medium supplemented with 10\% (v/v) FBS (Sigma-Aldrich Co.), 100 units/mL of penicillin, and $100 \mu \mathrm{g} / \mathrm{mL}$ of streptomycin (PAA Laboratories Gesellschaft m.b.H., Pasching, Austria). The cell count was measured with a hemocytometer by the trypan blue dye exclusion method.

\section{Splenic lymphocyte proliferation assay}

Lymphocytes were prepared from the spleens of control and treated rats, and proliferation was determined on liquid scintillation counter by using ${ }^{3} \mathrm{H}$-thymidine. ${ }^{24}$ Briefly, $4 \times 10^{5}$ cells $/ \mathrm{mL}$ in RPMI-1640 medium with 10\% (v/v) FBS, 100 units/mL of penicillin, and $0.1 \mathrm{mg} / \mathrm{mL}$ of streptomycin were seeded into 96-well plates $(200 \mu \mathrm{L} /$ well $)$ either in the presence or absence of mitogens. The spleen cells were then cultured at $37^{\circ} \mathrm{C}$ for 72 hours in a humid, saturated atmosphere containing $5 \% \mathrm{CO}_{2}$ in the presence of Con A $(5 \mu \mathrm{g} / \mathrm{mL})$ and LPS $(10 \mu \mathrm{g} / \mathrm{mL})$. Con A was added as a T-cell stimulant, whereas LPS as a B-cell stimulant. After 48 hours, the cultures were incubated with ${ }^{3} \mathrm{H}$-thymidine $(0.5 \mu \mathrm{Ci} /$ well $)$. After incubation, the cells were harvested on glass fiber filters, using Nunc cell harvester, and the thymidine incorporation was determined using liquid scintillation counter by adding $5 \mathrm{~mL}$ of scintillation fluid. The results were expressed as stimulation index, which was calculated using mean count per minute values.

\section{T-lymphocyte phenotyping by flow cytometric analysis}

Splenocytes cell suspension was analyzed by FACS to enumerate the T-lymphocytes subset population, using a method previously described. ${ }^{25}$ Antibodies utilized were FITC-conjugated CD8 for enumerating CD8+ T-lymphocytes and PE-conjugated CD4 for enumerating CD4+ T-lymphocytes. Briefly, splenocytes $\left(1 \times 10^{6}\right.$ cells $\left./ \mathrm{mL}\right)$ were incubated with $10 \mu \mathrm{L}$ FITC-conjugated anti-CD3, anti-CD8, and PE-conjugated anti-CD4 antibodies for 30 minutes. The acquisition and analysis were performed by multicolor FACS using CellQuest Pro software. The results were expressed in percentage of CD4+/CD8+ expression.

\section{Measurement of Th I/Th2 cytokines}

The whole blood collected from euthanized rats was centrifuged $(3,000 \times g)$ at $4^{\circ} \mathrm{C}$ for 10 minutes, and the serum was separated. The serum levels of IL-2, IL-4, IL-12, IFN- $\gamma$, and TNF- $\alpha$ were quantitatively determined using 5-plex magnetic beads-based ProcartaPlex rat immunoassay kit (eBioscience). The test was performed as per manufacturer's instructions. Briefly, antibody-coated magnetic beads were captured by adding $50 \mu \mathrm{L}$ of beads to each well of 96-well plates, which was inserted into the magnetic plate washer. A total of $25 \mu \mathrm{L}$ of serum samples were mixed with the captured antibody-coated magnetic beads. Subsequently, $25 \mu \mathrm{L}$ of assay buffer was added to each well and incubated for 2 hours on a magnetic shaker with $500 \mathrm{rpm}$ speed at the room temperature in the dark. Afterward, beads were washed thrice with wash buffer. After washing, $25 \mu \mathrm{L}$ of detection antibody was mixed into each well and samples were further incubated for 30 minutes at the room temperature in the dark. The washing steps were repeated after incubation as mentioned previously. Later, $50 \mu \mathrm{L}$ of streptavidin PE solution was added into each well and incubated for 30 minutes at room temperature. After incubation, the washing steps were repeated. Lastly, $120 \mu \mathrm{L}$ of reading buffer was added to each well and the plate was read on Luminex instrument to determine the concentration of cytokine.

\section{Statistical analysis}

The results are expressed as mean \pm standard deviation. Data were analyzed using a one-way analysis of variance followed by Dunnett's test using GraphPad Prism 5 software (GraphPad Software, Inc., La Jolla, CA, USA). $P<0.05$ was considered to be statistically significant.

\section{Results}

\section{Standardization of TCE}

The TCE was standardized on the basis of two marker compounds, syringin and magnoflorine. The reversed-phase HPLC chromatogram of $80 \%$ ethanol extract of TC exhibited peaks of syringin and magnoflorine corresponding to retention times at $6.360 \pm 0.072$ minutes and $20.967 \pm 0.208$ minutes, respectively (Figure 2). The quantitative determination of marker compounds by HPLC indicated that TCE contained syringin and magnoflorine at $466.92 \pm 2.23 \mu \mathrm{g} / \mathrm{mL}$ and $281.21 \pm 2.078 \mu \mathrm{g} / \mathrm{mL}$, respectively. The calibration curve plotted for the standard solution of syringin over the concentration 

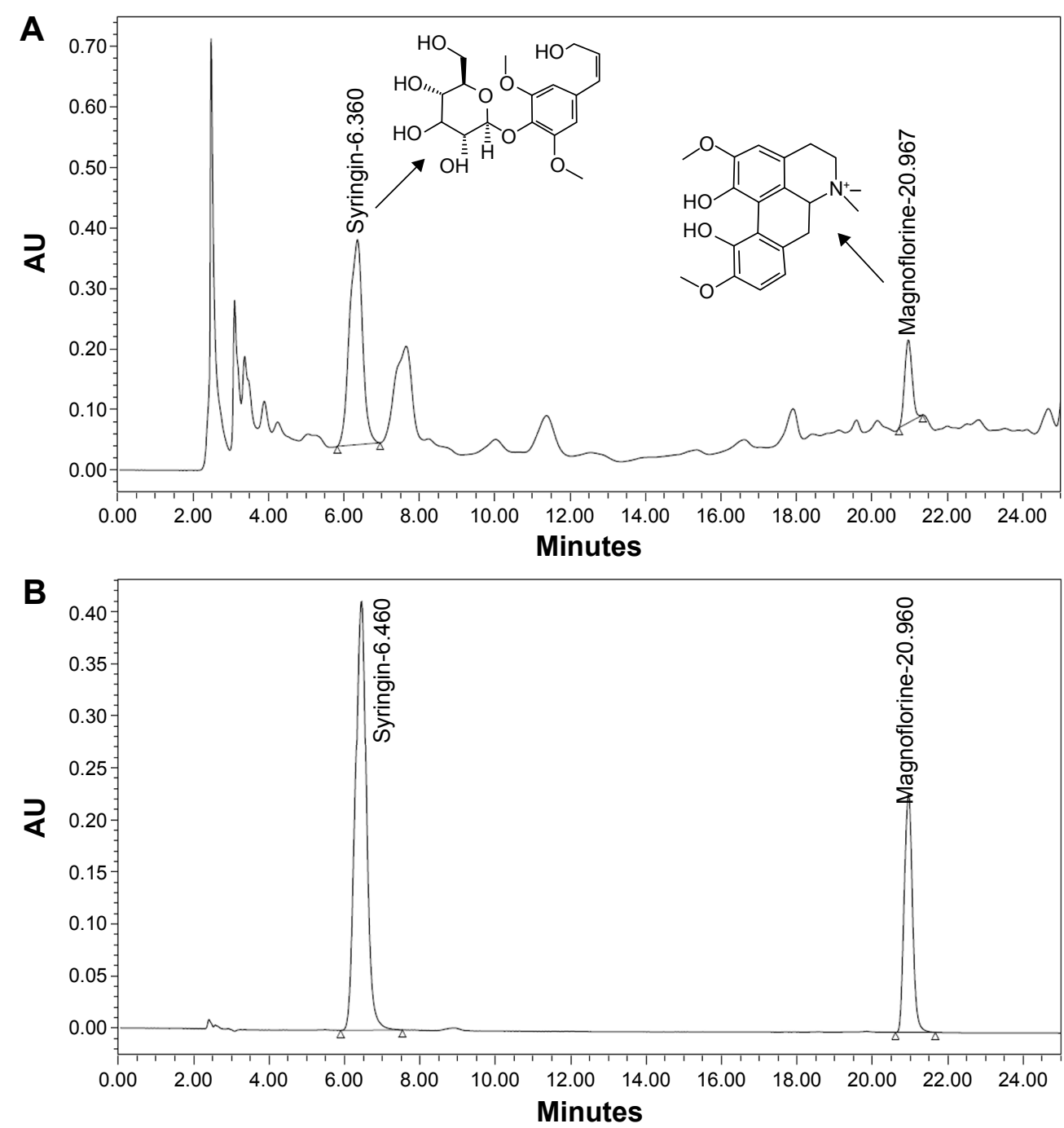

Figure 2 Standardization of TC $80 \%$ ethanol extract with syringin and magnoflorine.

Notes: (A) HPLC chromatogram of TC $80 \%$ ethanol extract. (B) HPLC chromatogram of syringin and magnoflorine. Detection was at $254 \mathrm{~nm}$.

Abbreviations: HPLC, high-performance liquid chromatography; TC, Tinospora crispa.

range of $62.5-1,000 \mu \mathrm{g} / \mathrm{mL}$ showed a correlation coefficient $\left(r^{2}\right)$ of 0.998 . The reproducibility of the results was confirmed by relative standard deviation (\%RSD). For intra-assay precision, $\% \mathrm{RSD} \%$ values of peak area and retention time were $0.77 \mu \mathrm{g} / \mathrm{mL}$ and 0.85 minutes, respectively, whereas for the interday assay, the $\%$ RSD of mean area under peak and retention time were $7.73 \mu \mathrm{g} / \mathrm{mL}$ and 1.98 minutes, respectively. The LOD and LOQ of syringin were found to be $3.11 \mathrm{ng} /$ $\mathrm{mL}$ and $9.443 \mathrm{ng} / \mathrm{mL}$, respectively. For magnoflorine, the calibration curve was linear over the concentration range of $62.5-1,000 \mu \mathrm{g} / \mathrm{mL}$ with a correlation coefficient $\left(r^{2}\right)$ of 0.9978 . The reproducibility of the results was demonstrated, where the $\%$ RSD values for intra-assay precision of peak area and retention time were $0.241 \mu \mathrm{g} / \mathrm{mL}$ and 0.0111 minutes, respectively, while the $\%$ RSD values for interday precision of peak area and retention time were $2.78 \mu \mathrm{g} / \mathrm{mL}$ and 0.583 minutes, respectively. The LOD and LOQ of magnoflorine were found to be $7.792 \mathrm{ng} / \mathrm{mL}$ and $23.613 \mathrm{ng} / \mathrm{mL}$, respectively.

\section{Effect of TCE on neutrophil migration}

To investigate the effect of TCE on the chemotactic activity of neutrophils, migration assay was performed using cell migration assay kit. Neutrophils were separated from rat blood and treated with extract and vehicle. The cells were allowed to migrate toward the chemoattractant fMLP. It was seen that migration increased in neutrophils obtained from extract-treated rats in contrast to controls. A dose-dependent increase in the number of migrated cells was observed, ie, increasing the dose lead to an increase in the number of migrated cells. The results in Figure 3 show that TCE significantly enhanced the transmigration of neutrophils. The maximal neutrophils migration upon stimulation by fMLP 


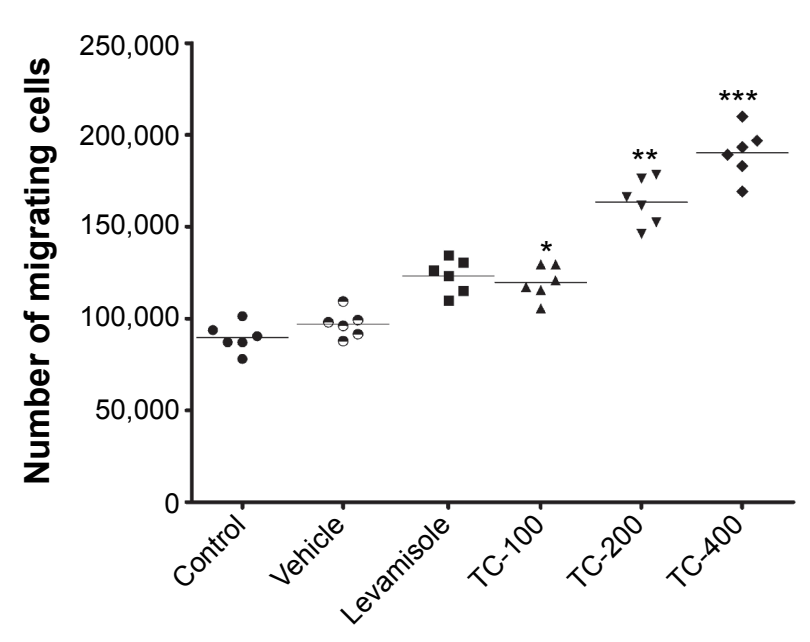

Figure 3 Effect of the ethanolic extract of TC $(100 \mathrm{mg} / \mathrm{kg}, 200 \mathrm{mg} / \mathrm{kg}$, and $400 \mathrm{mg} / \mathrm{kg})$ on neutrophil migration.

Notes: $* P<0.05, * * P<0.01, * * * P<0.001$ are the significant differences compared with control determined by one-way ANOVA followed by Dunnett's test.

Abbreviations: TC, Tinospora crispa; ANOVA, analysis of variance.

was observed at a dose of $400 \mathrm{mg} / \mathrm{kg}$. There was a significant increase in the number of migrating cells.

\section{Effect of TCE on Mac-I expression}

CD11b, a pro-inflammatory integrin, also known as Mac-1 present on neutrophils, plays a central role in adhesion and extravasation of neutrophils. The effects of TCE on Mac-1 expressions by neutrophils were evaluated by FACS. Neutrophils isolated from TCE-treated groups, when evaluated for the Mac-1 expression, were found to elicit enhanced the expression of Mac-1 when compared to the untreated group. The expression of Mac-1 increased with the increasing dose. At the doses of $200 \mathrm{mg} / \mathrm{kg}$ and $400 \mathrm{mg} / \mathrm{kg}$, neutrophils showed significant enhancement $(P<0.01)$ in the expression of $\mathrm{CD} 11 \mathrm{~b}$ positive cell population compared to the control group (Figure 4).

\section{Effect of TCE on neutrophil phagocytic activity}

To evaluate the effect of TCE on phagocytosis, the neutrophils isolated from control and test rats were incubated with FITC-labeled E. coli. All animals treated with the doses of $100 \mathrm{mg} / \mathrm{kg}, 200 \mathrm{mg} / \mathrm{kg}$, and $400 \mathrm{mg} / \mathrm{kg}$ exhibited an increase in the phagocytosis of FITC-labeled E. coli. The phagocytic activity is expressed by a percentage of phagocytosis as shown in Figure 5. No significant change in phagocytosis was seen at a dose of $100 \mathrm{mg} / \mathrm{kg}$ as compared to control. However, the increases at doses of $200 \mathrm{mg} / \mathrm{kg}$ and $400 \mathrm{mg} / \mathrm{kg}$ were found to be significant as compared to the control group $(P<0.01)$. The optimal phagocytizing of bacteria was at $400 \mathrm{mg} / \mathrm{kg}$ dose of TCE. The phagocytic activity at $400 \mathrm{mg} / \mathrm{kg}$ dose was higher than that of the positive group.

\section{Effect of TCE on splenocyte proliferation}

To evaluate the effect of TCE on proliferation capacity, splenocytes were harvested from control and test group animals. Mitogens such as LPS and Con A are known to specifically induce the proliferation of splenocytes. The effect of TCE on Con A- and LPS-stimulated splenocyte proliferation in immunized animals is shown in Figure 6. The lymphocyte proliferation was studied using liquid scintillation counter. The normal splenic lymphocyte proliferation ratio induced by Con A or LPS in animals treated with vehicle was taken as control. It was observed that TCE enhanced the proliferative response of splenocyte stimulated with Con $\mathrm{A}(5 \mu \mathrm{g} / \mathrm{mL})$ and LPS $(10 \mu \mathrm{g} / \mathrm{mL})$. The increase in proliferation was observed in a dose-dependent manner. The proliferative responses of splenic lymphocytes from rats treated with TCE at doses of $200 \mathrm{mg} / \mathrm{kg}$ and $400 \mathrm{mg} / \mathrm{kg}$ were significantly higher than control for both T-cell and B-cell mitogens (Con A and LPS, respectively). The cellular proliferation in both Con A and LPS-stimulated splenocytes in the TCE-treated group was optimal at the dose of $400 \mathrm{mg} / \mathrm{kg}$, and there was a two fold increase in the cellular proliferation as compared to the vehicle-treated group.

\section{Effect of TCE on T-lymphocytes phenotyping}

Analysis of the expression of T-cell subsets CD4+, Th cells, and CD8+ cytotoxic T-cells was performed using flow cytometer to investigate whether TCE affected the differentiation of T-cells. Splenocytes isolated from TCE-treated and -untreated immunized mice were stained with FITC-labeled anti-CD3 and anti-CD19 antibodies. The results of T-cell phenotyping are reported in Table 1 and Figure 7. It was observed that animals treated with TCE enhanced the expression of CD4+, Th cells, and CD8+ cytotoxic T-cell in comparison with control. There was a dose-dependent significant enhancement in T-cell subpopulation. The maximum stimulation response by TCE was seen at $400 \mathrm{mg} / \mathrm{kg}$ dose that was significantly higher than immunostimulatory standard drug levamisole at the dose of $10 \mathrm{mg} / \mathrm{kg}$.

\section{Effect of TCE on Th I (TNF- $\alpha$, IL-2, and IFN- $\gamma$ ) and Th2 (IL-4) cytokines}

The effect of TCE on the release of Th1 and Th2 cytokines was determined. The level of cytokines in the serum of rats from each group was analyzed by bead-based multiplex 

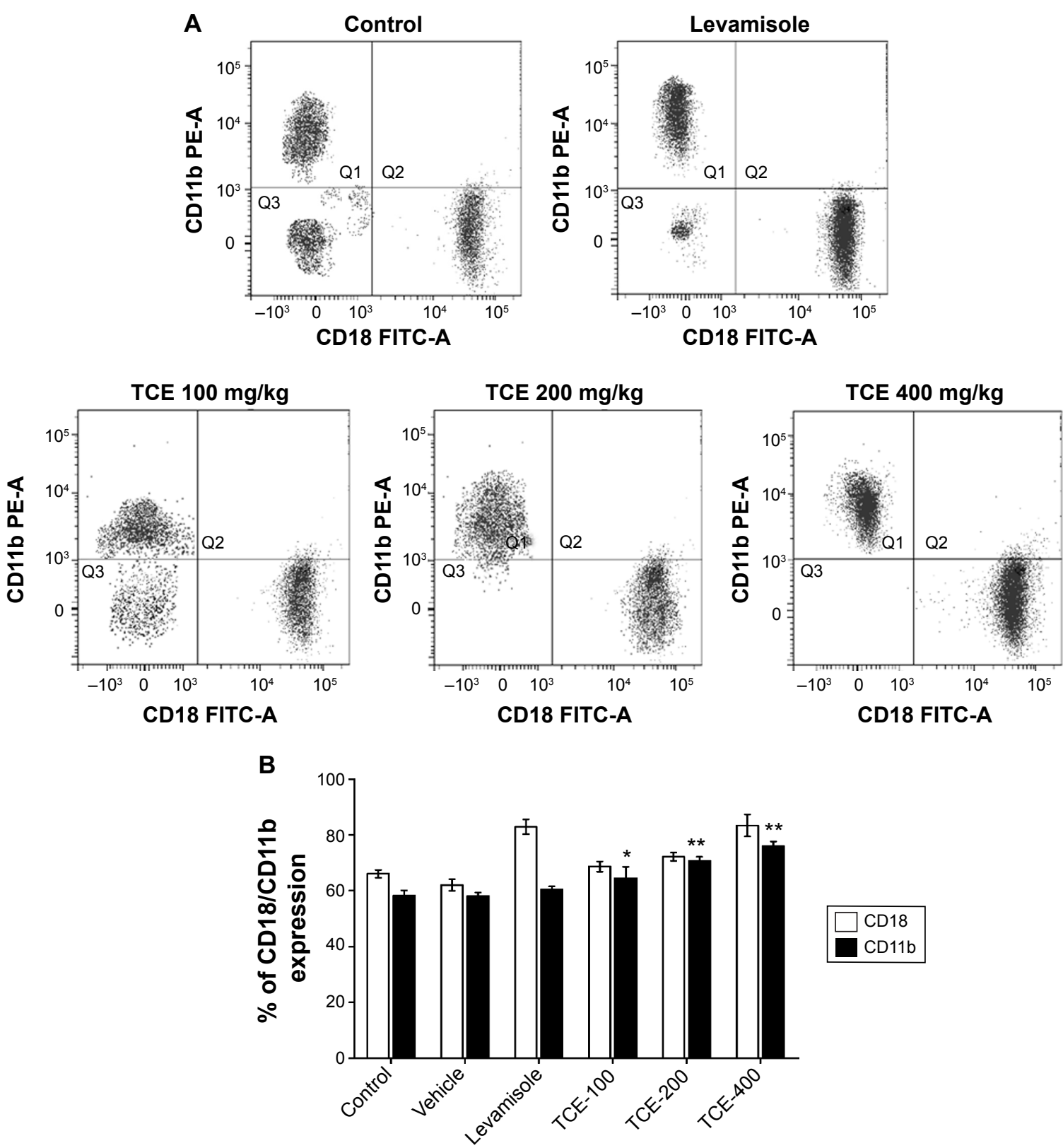

Figure 4 Flow cytometric evaluation of the effect of ethanolic extract of Tinospora crispa ( $100 \mathrm{mg} / \mathrm{kg}, 200 \mathrm{mg} / \mathrm{kg}$, and $400 \mathrm{mg} / \mathrm{kg})$ on expression (\%) of CDI8 and CDI lb on neutrophils.

Notes: (A) Represents FACS analysis results, while (B) represents the statistically transformed data of six animals, expressed as mean \pm SD values. $* P<0.05$ and $* * P<0.0$ I are the significant differences compared with the control group determined by one-way ANOVA followed by Dunnett's test.

Abbreviations: FACS, flow cytometry; SD, standard deviation; ANOVA, analysis of variance; PE, phycoerythrin; FITC, fluorescein isothiocyanate; TCE, Tinospora crispa extract.

assay. The results are shown in Figure 8. The levels of Th1 cytokines (TNF- $\alpha$, IL-2, and IFN- $\gamma$ ) were significantly increased (in a dose-dependent manner) in sera of rats treated with different doses of TCE when compared to control. The increase in TNF- $\alpha$ was almost 2.5 -fold, in IFN- $\gamma$ was almost threefold, and in IL-2 was fourfold at $400 \mathrm{mg} / \mathrm{kg}$ dose as compared to the control group. The effect of TCE on IL-4 (Th2 cytokine) was determined (Figure 8). It was observed that the expression of IL-4 was significantly enhanced in animals that received TCE. Dose-dependent increase in the level of IL-4 was observed with the maximum effect at $400 \mathrm{mg} / \mathrm{kg}$. There was almost fourfold increase in the IL-4 level compared to the control group at $400 \mathrm{mg} / \mathrm{kg}$.

\section{Discussion}

The immune system is the vital defense against tumor, cancer growth, and infectious diseases. A strong immune system comprises elements that are in balance with one another; 

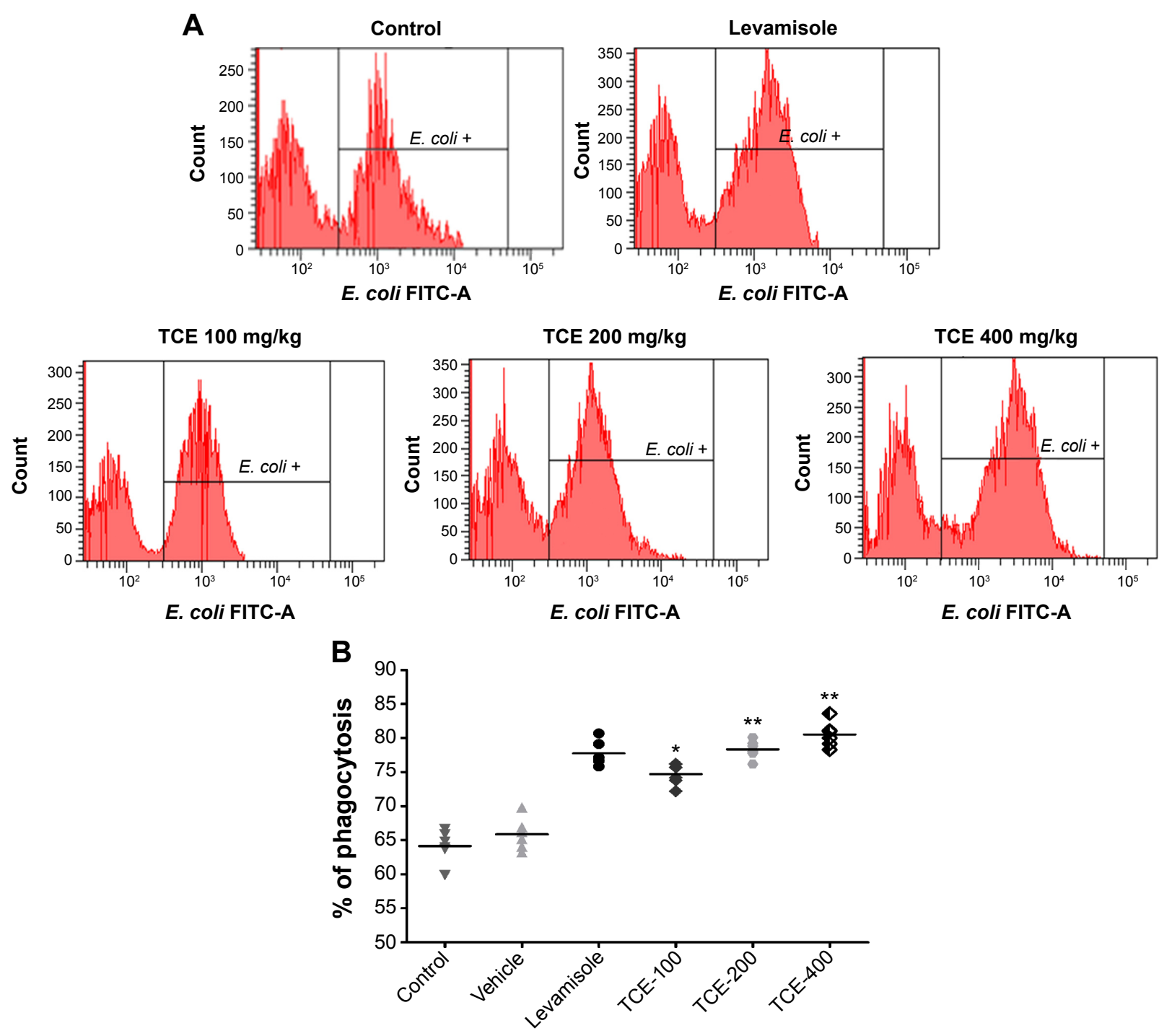

Figure 5 Flow cytometric evaluation of the effect of the ethanolic extract of Tinospora crispa (I00 mg/kg, $200 \mathrm{mg} / \mathrm{kg}$, and $400 \mathrm{mg} / \mathrm{kg})$ on phagocytosis of FITC-conjugated E. coli by neutrophils.

Notes: (A) Represents FACS analysis results, while $(\mathbf{B})$ represents the statistically transformed data of six animals, expressed as mean \pm SD values. $* P<0.05$ and $* * P<0.0$ I are the significant differences compared with the control group determined by one-way ANOVA followed by Dunnett's test.

Abbreviations: FITC, fluorescein isothiocyanate; FACS, flow cytometry; SD, standard deviation; ANOVA, analysis of variance; TCE, Tinospora crispa extract.

if this balance is disturbed, our immune system will be incapable to protect the body against harmful substances. The side effects linked with allopathic drugs along with their high cost have imposed the need for search of immunomodulatory agents that exert less adverse effects and can be administered for a longer duration to attain a continuous immune activation for the prevention of various diseases. Immunomodulation using medicinal plants can provide a substitute to conventional chemotherapy for a range of diseases, especially when host defense mechanism has to be activated under the conditions of impaired immune response or when a selective immunosuppression is needed in situations such as autoimmune disorders. There are several diseases where immunostimulant drugs are needed to overcome the immunosuppression induced by drugs or environmental factors, and immunosuppressants are required where there is undesired immunopotentiation. There is a strong necessity of the drugs that can enhance the immune system to combat the immunosuppressive consequences caused by stress, chronic diseases, and conditions of impaired immune responsiveness.

Recently, medicinal plants and their products have been commonly used to modulate immune response. ${ }^{26}$ Though medicinal plants have been investigated for diverse pharmacologic activities, the immunomodulatory potential of TC still remains unknown. This investigation deals with the TC that was used for its immunomodulatory activity. In this study, TCE at the indicated therapeutic doses by oral route 


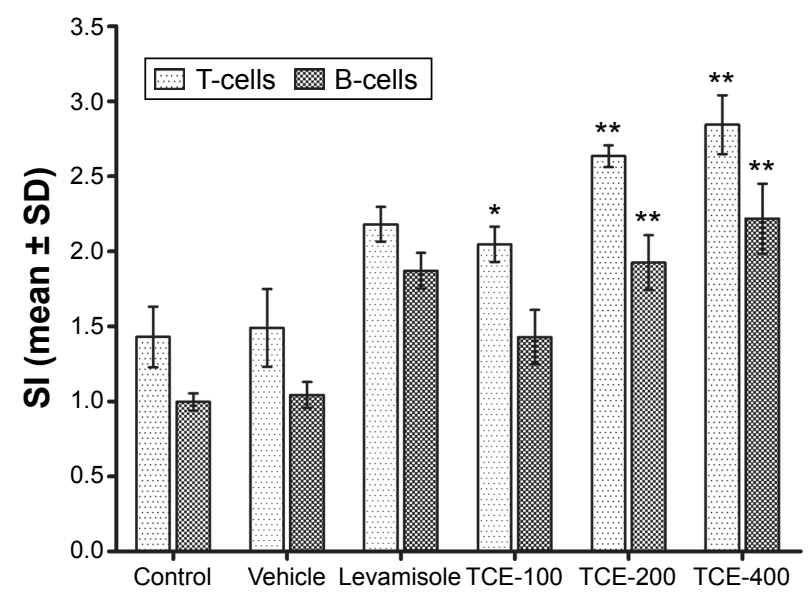

Figure 6 Effect of ethanolic extract of Tinospora crispa $(100 \mathrm{mg} / \mathrm{kg}, 200 \mathrm{mg} / \mathrm{kg}$, and $400 \mathrm{mg} / \mathrm{kg}$ ) on proliferation of T- and B-lymphocytes.

Notes: Splenocyte proliferation is expressed as SI. Data expressed as mean \pm SD values of six animals. $* P<0.05$ and $* * P<0.01$ are significant differences compared with the control group determined by one-way ANOVA followed by Dunnett's test. Abbreviations: SI, stimulation index; SD, standard deviation; ANOVA, analysis of variance; TCE, Tinospora crispa extract.

was found to be safe as no animal mortality happened during this period. The general appearance of TCE-treated animals did not show any change compared to untreated animals.

Neutrophils are an important component of the innate immune system, with a main role in the clearance of extracellular pathogens..$^{27}$ Both localization and neutralization of microorganisms are key neutrophil functions that are coordinated by specific inflammatory mediators released from the site of infection. ${ }^{28}$ The recruitment of leukocytes toward stimuli is an important step in immune response for generation of effective immune response. Integrins, cell surface glycoproteins, mediate the migration of neutrophils to the inflammatory site. Integrin family molecules, especially $\beta_{2}$-integrin subfamily molecules, which are commonly expressed by leukocytes, mediate the strong adhesion by interacting with a variety of cell components and super family molecules of immunoglobulins. The regulation of the binding of $\beta_{2}$-integrin to the ligands plays a key role in leukocyte adhesion to the vascular endothelium and migration of circulating leukocytes to stimulus. ${ }^{29-31} \mathrm{CD} 11 \mathrm{~b}$ (also known as Mac-1) is an important $\beta_{2}$-integrin expressed on the surface of leukocytes. In this study, the effect of TCE extract on Mac-1 expression in stimulated neutrophils was investigated. Neutrophils isolated from TCE-treated groups of rats, when evaluated for the Mac-1 expression, were found to cause enhanced expression of $\beta_{2}$-integrin CD11b/CD18 (Mac-1) when compared to untreated control groups. The improved expression of Mac-1 provided understanding into the immune activation machinery through TCE. The expression of these integrins is positively influenced by inflammatory mediators such as IL-2 and INF- $\boldsymbol{\gamma}^{32}$ The improvement in ex vivo fMLP-induced chemotaxis of neutrophils isolated from rats pretreated with TCE indicates the potential activity of TCE on the migration of neutrophil, which could be due to the upregulation of Mac-1 as fMLP involved in stimulation of neutrophils chemotaxis by a mechanism that is mediated by Mac-1. Presently, the immunomodulatory potential of TCE was investigated comprehensively on the modulation of both $\mathrm{T}$ - and B-cells to T-dependent antigen SRBC. The proliferation of B- and T-lymphocytes is a response to the stimulation induced by antigens or mitogens. Cellular proliferation induced by Con A is commonly used to detect T-lymphocyte immunity, and LPS-induced activation of B-cells indicates B-lymphocyte immunity. ${ }^{33}$ The TCE treatment enhanced the Con A and LPS-induced lymphocyte proliferation.

To further elucidate the mechanism of TCE as an immunomodulatory agent, the effects of TCE on both CD4+ and CD8+ spleen T-lymphocyte populations in SRBCimmunized animals were analyzed by flow cytometric assay. T-lymphocytes, the vital part of the defensive immune system, are differentiated into two different subsets according to their specific membrane molecule, which are CD4+ and CD8+ T-lymphocytes. Since T-cells play a key role in regulating the immune responses by being responsible for cell-mediated immunity, in a stable immune system, fast

Table I Effects of various concentrations of Tinospora crispa extract on T-lymphocyte phenotypes

\begin{tabular}{lllll}
\hline Group & Treatment & Dose $(\mathbf{m g} / \mathbf{k g})$ & \multicolumn{2}{c}{ \% of CD4+/CD8+ expression } \\
\cline { 3 - 5 } & & & CD3+CD4+ & CD3+CD8+ \\
\hline I & Control & & $49.085 \pm 2.88$ & $20.255 \pm I .61$ \\
II & Vehicle & 10 & $49.655 \pm 1.64$ & $21.580 \pm 1.85$ \\
III & Levamisole & 100 & $71.675 \pm 3.17 * *$ & $40.615 \pm 4.97 * *$ \\
IV & Ethanolic extract of T. crispa & 200 & $63.660 \pm 3.64 *$ & $34.785 \pm 4.95 *$ \\
V & Ethanolic extract of T. crispa & 400 & $83.500 \pm 3.89 * *$ & $46.725 \pm 2.54 * *$ \\
VI & Ethanolic extract of T. crispa & $87.745 \pm 4.09 * *$ & $49.345 \pm 2.76 * *$ \\
\hline
\end{tabular}

Notes: Data are mean percentage expression of CD4 and CD8 cells. The values represent the mean \pm standard error $(n=6)$. $* P<0.05$ and $* * P<0.00$ I were significant compared with the control group. 

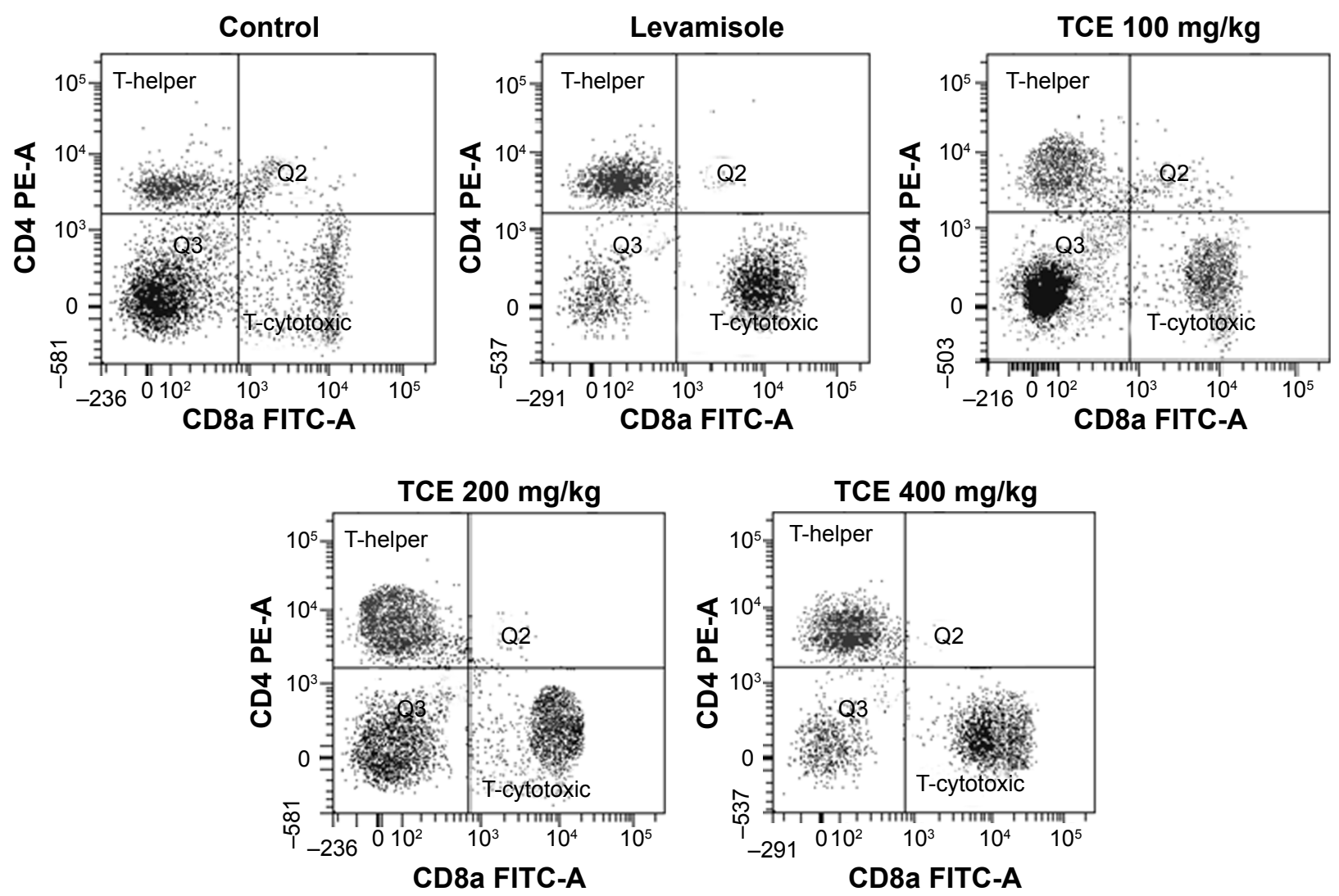

Figure 7 Flow cytometric evaluation of the effect of the ethanolic extract of Tinospora crispa (100 mg/kg, $200 \mathrm{mg} / \mathrm{kg}$, and $400 \mathrm{mg} / \mathrm{kg})$ on T-lymphocyte phenotypes (CD4 and CD8).

Abbreviations: PE, phycoerythrin; FITC, fluorescein isothiocyanate; TCE, Tinospora crispa extract.

T-cell proliferation following antigen stimulus is governed by following differentiation into effector cells. Being main protectors of the host against diseases, lymphocyte activation and proliferation are vital during onslaught of infection or other pathological conditions. The agents responsible for the proliferation of the CD4+ and CD8+ cells have significant therapeutic potential for patients who are suffering from CD4+ lymphopenia caused by numerous infectious diseases, drugs, or cancer. ${ }^{34} \mathrm{TCE}$ at different oral doses significantly improved the percentage of CD4+ and CD8+ T-lymphocytes in SRBC-immunized animals. The differentiation of T-cells into its subtypes CD4+ and CD8+ T-populations was seen to be doubled in the animals treated with TCE, thus explaining its possible role in cell-mediated immune activation.

Besides, the Th cells are a type of T-lymphocytes that assist to enhance or potentiate the activity of other immune cells by releasing T-cell cytokines. The proliferating Th cells are capable of developing into effector T-cells, which additionally differentiate into two main functionally distinctive subtypes of cells called as Th1 and Th2 cells. ${ }^{35}$ It is well known that Th cells and cytotoxic $\mathrm{T}$ lymphocyte responses are linked with the enhancement of CD4+ and
CD8+ T-lymphocytes, respectively. The Th1 lymphocytes characterized by the production of IL-2, IFN- $\gamma$, and TNF- $\alpha$ add to cellular immunity, while Th2 lymphocytes, mostly involved in humoral immunity, produce IL-4, IL-5, and IL-10. Th1 immunity defends against cancer progression and several intracellular infectious diseases, while Th2 immunity is beneficial against extracellular pathogenic infections and autoimmune diseases. ${ }^{36}$ Therefore, the balance among Th1 and Th2 release of cytokine plays an essential role in the determination of direction and outcome of an immune response. The results obtained from the study revealed that TCE enhanced the production of Th1 and Th2 cytokines. The recent and previous studies showed that both CD4+ and CD8+ T-cells were able to control immune response by the regulation of cytokines. According to a recent research, the CD4+ T-cells differentiate into one of the two effector phenotypes where Th1 cells drive the immune response toward a cell-mediated immune response, while Th2 cells stimulate a humoral or allergic response. ${ }^{37,38}$ The augmentation of B- and T-cells with TCE might be due to the Th1/Th2 cytokinemediated mechanism. Hence, based on our discoveries, we propose that TCE may augment cell-mediated and humoral 

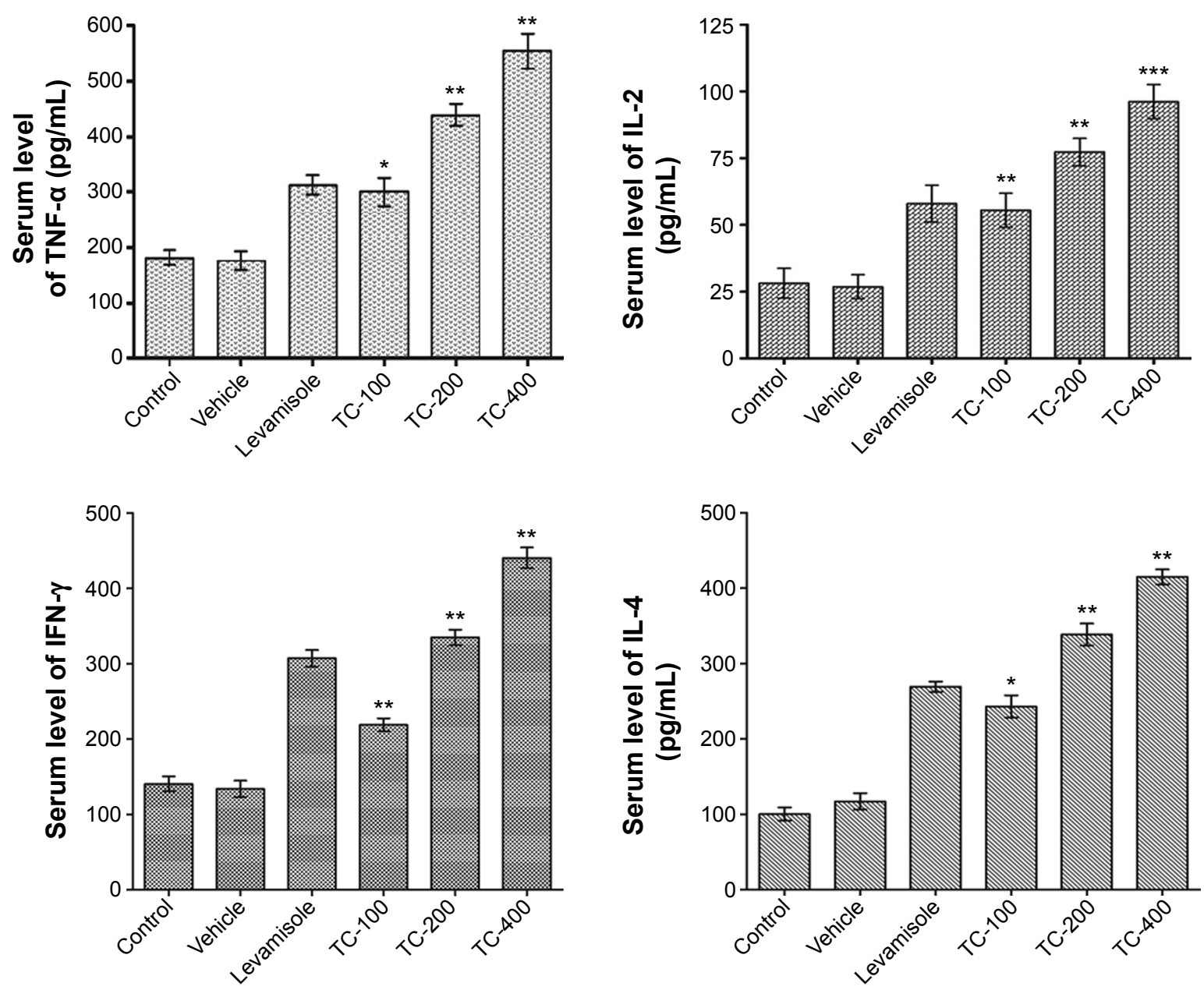

Figure 8 Effect of ethanolic extract of Tinospora crispa (100 mg/kg, $200 \mathrm{mg} / \mathrm{kg}$, and $400 \mathrm{mg} / \mathrm{kg})$ Th $/ /$ Th2 cytokines.

Notes: Data expressed as mean \pm SD values of six animals. $* P<0.05, * * P<0.01$ and $* * * P<0.001$ are the significant differences compared with the control group determined by one-way ANOVA followed by Dunnett's test.

Abbreviations: SD, standard deviation; ANOVA, analysis of variance; TNF- $\alpha$, tumor necrosis factor alpha; TC, Tinospora crispa; IFN- $\gamma$, interferon gamma; IL, interleukin.

immune functions by increasing the secretion of Th1 and Th2 cytokines.

\section{Conclusion}

The results demonstrate that the extract of TC was able to activate the cell-mediated immunity by enhanced chemotactic and phagocytic activity of neutrophils along with enhanced expression of proinflammatory integrin Mac-1. Furthermore, TCE also enhanced the proliferation of splenocytes, simultaneously augmenting the production of Th1 and Th2 cytokines. The present findings suggest that the ethanolic extract of TC possesses potent immunostimulatory properties. As the study demonstrates that the ethanol extract of TC could improve immune function, it can be a potential immune-therapeutic agent possibly beneficial in enhancing the immune response in immune-compromised diseases.
However, the pharmacologically active ingredients in TC and the signaling pathways involved in the immunostimulation also remain to be further elucidated.

\section{Acknowledgment}

This research is supported by a grant (No 02-01-02-SF0932) from the Ministry of Science, Technology and Innovation, Malaysia.

\section{Disclosure}

The authors declare no conflicts of interest in this work.

\section{References}

1. Parkin J, Cohen B. An overview of the immune system. Lancet. 2001; 357(9270):1777-1789.

2. Turvey SE, Broide DH. Innate immunity. J Allergy Clin Immunol. 2010; 125(2 suppl 2):24. 
3. Shukla S, Bajpai V, Kim M. Plants as potential sources of natural immunomodulators. Rev Environ Sci Biotechnol. 2014;13(1):17-33.

4. Patwardhan B, Gautam M. Botanical immunodrugs: scope and opportunities. Drug Discov Today. 2005;10(7):495-502.

5. Ghule BV, Yeole PG. In vitro and in vivo immunomodulatory activities of iridoids fraction from Barleria prionitis Linn. J Ethnopharmacol. 2012; 141(1):424-431

6. Alexander CP, Kirubakaran CJ, Michael RD. Water soluble fraction of Tinospora cordifolia leaves enhanced the non-specific immune mechanisms and disease resistance in Oreochromis mossambicus. Fish Shellfish Immunol. 2010;29(5):765-772.

7. Kushwaha S, Roy S, Maity R, et al. Chemotypical variations in with ania somnifera lead to differentially modulated immune response in BALB/c mice. Vaccine. 2012;30(6):1083-1093.

8. Cruz GV, Pereira PV, Patrício FJ, et al. Increase of cellular recruitment, phagocytosis ability and nitric oxide production induced by hydroalcoholic extract from Chenopodium ambrosioides leaves. $J$ Ethnopharmacol. 2007;111(1):148-154.

9. Smith MJ, Germolec DR, Frawley RP, White KL Jr. Immunomodulatory effects of black cohosh (Actaea racemosa) extract in female B6C3F1/N mice. Toxicology. 2013;308:146-157.

10. Gautam M, Diwanay S, Gairola S, Shinde Y, Patki P, Patwardhan B. Immunoadjuvant potential of Asparagus racemosus aqueous extract in experimental system. J Ethnopharmacol. 2004;91(2-3):251-255.

11. Ren Z, He C, Fan Y, et al. Immuno-enhancement effects of ethanol extract from Cyrtomium macrophyllum (Makino) Tagawa on cyclophosphamide-induced immunosuppression in BALB/c mice. J Ethnopharmacol. 2014;155(1):769-775.

12. Yuandani, Ilangkovan M, Jantan I, Mohamad HF, Husain K, Abdul Razak AF. Inhibitory effects of standardized extracts of Phyllanthus amarus and Phyllanthus urinaria and their marker compounds on phagocytic activity of human neutrophils. Evid Based Complement Altern Med. 2013;603634(10):2.

13. Nudo LP, Catap ES. Immunostimulatory effects of Uncaria perrottetii (A. Rich.) Merr. (Rubiaceae) vinebark aqueous extract in Balb/C mice. $J$ Ethnopharmacol. 2011;133(2):613-620.

14. Jayathirtha MG, Mishra SH. Preliminary immunomodulatory activities of methanol extracts of Eclipta alba and Centella asiatica. Phytomedicine. 2004;11(4):361-365.

15. Choudhary MI, Ismail M, Shaari K, et al. cis-Clerodane-type furanoditerpenoids from Tinospora crispa. J Nat Prod. 2010;73(4):541-547.

16. Li S, Long $\mathrm{C}$, Liu F, et al. Herbs for medicinal baths among the traditional Yao communities of China. J Ethnopharmacol. 2006;108(1):59-67.

17. Rungruang $\mathrm{T}$, Boonmars $\mathrm{T}$. In vivo antiparasitic activity of the Thai traditional medicine plant-Tinospora crispa-against Plasmodium yoelii. Southeast Asian J Trop Med Public Health. 2009;40(5):898-900.

18. Praman S, Mulvany MJ, Williams DE, Andersen RJ, Jansakul C. Hypotensive and cardio-chronotropic constituents of Tinospora crispa and mechanisms of action on the cardiovascular system in anesthetized rats. J Ethnopharmacol. 2012;140(1):166-178.

19. Praman S, Mulvany MJ, Williams DE, Andersen RJ, Jansakul C. Crude extract and purified components isolated from the stems of Tinospora crispa exhibit positive inotropic effects on the isolated left atrium of rats. J Ethnopharmacol. 2013;149(1):123-132.
20. Abood WN, Fahmi I, Abdulla MA, Ismail S. Immunomodulatory effect of an isolated fraction from Tinospora crispa on intracellular expression of INF-gamma, IL-6 and IL-8. BMC Complement Altern Med. 2014;14(205):1472-6882.

21. Kumar S, Jyoti A, Keshari RS, Singh M, Barthwal MK, Dikshit M. Functional and molecular characterization of NOS isoforms in rat neutrophil precursor cells. Cytometry A. 2010;77(5):467-477.

22. Verma S, Hoffmann FW, Kumar M, et al. Selenoprotein K knockout mice exhibit deficient calcium flux in immune cells and impaired immune responses. J Immunol. 2011;186(4):2127-2137.

23. Wang C, Yu X, Cao Q, et al. Characterization of murine macrophages from bone marrow, spleen and peritoneum. BMC Immunol. 2013;14(6):1471-2172.

24. Varalakshmi C, Ali AM, Pardhasaradhi BV, Srivastava RM, Singh S, Khar A. Immunomodulatory effects of curcumin: in-vivo. Int Immunopharmacol. 2008;8(5):688-700.

25. Gupta A, Khajuria A, Singh J, et al. Immunomodulatory activity of biopolymeric fraction RLJ-NE-205 from Picrorhiza kurroa. Int Immunopharmacol. 2006;6(10):1543-1549.

26. Bhat BA, Dhar KL, Puri SC, et al. Isolation, characterization and biological evaluation of datura lactones as potential immunomodulators. Bioorg Med Chem. 2005;13(24):6672-6677.

27. Stuart LM, Ezekowitz RA. Phagocytosis and comparative innate immunity: learning on the fly. Nat Rev Immunol. 2008;8(2):131-141.

28. Phillipson M, Kubes P. The neutrophil in vascular inflammation. Nat Med. 2011;17(11):1381-1390.

29. Williams MR, Azcutia V, Newton G, Alcaide P, Luscinskas FW. Emerging mechanisms of neutrophil recruitment across endothelium. Trends Immunol. 2011;32(10):461-469.

30. Lub M, van Kooyk Y, Figdor CG. Ins and outs of LFA-1. Immunol Today. 1995;16(10):479-483.

31. Azar RR, McKay RG, Kiernan FJ, et al. Coronary angioplasty induces a systemic inflammatory response. Am J Cardiol. 1997;80(11): 1476-1478.

32. Stewart M, Thiel M, Hogg N. Leukocyte integrins. Curr Opin Cell Biol. 1995;7(5):690-696.

33. Wang H, Wang M, Chen J, et al. A polysaccharide from Strongylocentrotus nudus eggs protects against myelosuppression and immunosuppression in cyclophosphamide-treated mice. Int Immunopharmacol. 2011; 11(11):1946-1953.

34. Khan S, Malik F, Suri KA, Singh J. Molecular insight into the immune up-regulatory properties of the leaf extract of Ashwagandha and identification of Th1 immunostimulatory chemical entity. Vaccine. 2009; 27(43):6080-6087.

35. Geginat J, Paroni M, Maglie S, et al. Plasticity of human CD4 T cell subsets. Front Immunol. 2014;5:630.

36. Kidd $\mathrm{P}$. Th1/Th2 balance: the hypothesis, its limitations, and implications for health and disease. Altern Med Rev. 2003;8(3):223-246.

37. Xu M, Zhao M, Yang R, Zhang Z, Li Y, Wang J. Effect of dietary nucleotides on immune function in Balb/C mice. Int Immunopharmacol. 2013; 17(1):50-56.

38. Abid S, Khajuria A, Parvaiz Q, et al. Immunomodulatory studies of a bioactive fraction from the fruit of Prunus cerasus in BALB/c mice. Int Immunopharmacol. 2012;12(4):626-634.
Drug Design, Development and Therapy

\section{Publish your work in this journal}

Drug Design, Development and Therapy is an international, peerreviewed open-access journal that spans the spectrum of drug design and development through to clinical applications. Clinical outcomes, patient safety, and programs for the development and effective, safe, and sustained use of medicines are a feature of the journal, which

\section{Dovepress}

has also been accepted for indexing on PubMed Central. The manuscript management system is completely online and includes a very quick and fair peer-review system, which is all easy to use. Visit http://www.dovepress.com/testimonials.php to read real quotes from published authors. 